\title{
EFEKTIFITAS STRATEGI PEMBELAJARAN ACTIVE LEARNING TIPE INDEX CARD MATCH DITINJUAU DARI KETERAMPILAN BERKOMUNIKASI TERHADAP HASIL BELAJAR IPA
}

\section{EFFECTIVITY OF LESSON STRATEGY OF ACTIVE LEARNING TYPE INDEX CARD MATCH VIEWED FROM COMMUNICATION SKILL TO THE SCIENCE LEARNING OUTCOMES}

\author{
Tias Ernawati*, Dita Setyawati \\ Program Studi Pendidikan IPA Fakultas Keguruan dan Ilmu Pendidikan Universitas Sarjanawiyata Taman \\ Siswa, Yogayakarta \\ *Email : tias.ernawati@ustjogja.ac.id
}

\begin{abstract}
Abstrak: Penelitian ini bertujuan untuk mengetahui: (1) perbedaan hasil belajar IPAkelas eksperimen dan kelas kontrol,(2) perbedaan hasil belajar IPA siswa kelompok keterampilan berkomunikasi tinggi dan rendah,(3) interaksi strategi pembelajaran dan keterampilan berkomunikasi terhadap hasil belajar IPA, (4) efektifitas strategi pembelajaran active learning tipe Index Card Match. Penelitian ini dilaksanakan di kelas VII SMP N 4 Sewon tahun pelajaran 2017/2018. Sampel diambil dengan teknik random sampling.Penelitian ini merupakan jenis penelitian quasi eksperiment. Teknik pengumpulan data menggunakan teknik tes, teknik angket, dan teknik dokumentasi. Teknik analisis data menggunakan Anava dua jalur.Hasil penelitian menunjukkan, (1) ada perbedaan hasil belajar IPA yang sangat signifikan antara kelas eksperimen dan kelas kontrol dengan $\mathrm{F}_{\mathrm{A} \text { hitung }}=$ 44,318 dan $\mathrm{p}=0,000$, (2) ada perbedaan yang sangat signifikan antara hasil belajar IPA pada keterampilan berkomunikasi tinggi dan rendah dengan $\mathrm{F}_{\mathrm{B} \text { hitung }}=259,557$ dan $\mathrm{p}=0,000$, (3) ada interaksi yang sangat signifikan antara strategi pembelajaran dan keterampilan berkomunikasi terhadap hasil belajar IPA pada $\mathrm{F}_{\mathrm{AB}}$ hitung $=7,064$ dan $\mathrm{p}=0,010$, (4) rerata hasil belajar kelas eksperimenlebih tinggi dari kelas kontrol sehingga strategi pembelajaran active learning tipe Index Card Match lebih efektif.
\end{abstract}

Kata Kunci: active learning, index card match, keterampilan berkomunikasi

\begin{abstract}
The objectives of this study are to describe: (1) difference of natural science learning outcomes in experimental class and controllingn class, (2)difference of natural science learning outcomes in high and low communication skill groups, (3) interaction of lesson strategy and communicatin skill to natural science learning outcome, (4) effectivity of lesson strategy of active learning type index card matchto natural science learning outcome. As a quasi experiment, this research was held in SMP N 4 Sewon involving seventh graders in the 2017/2018academicyear. The data collection methods include documentation, questionnaire and test of science learning outcomes. The Anava Two Ways was used to analize the data. The results show: (1) a very significant difference of natural science learning outcomes in experimental class and control class from which $\mathrm{F}_{\mathrm{A} \text { count }}=$ 44,318 and $p=0,000$ could be obtained, (2) a very significant difference of natural science learning outcomes in high and low communication skill groupsis concluded from $F_{B}$ count $=259.557$ and $p=0,000$;(3)there are interaction of lesson strategy and communicatin skill to natural science learning outcomefrom which $\mathrm{F}_{\mathrm{AB} \text { count }}=$ 7.064 and $p=0,010$ could be gain, (4)The average score of the natural science students' learning outcomes in experimental classis higher than controlling class, thus lesson strategy of active learning type index card match is mere effective.
\end{abstract}

Keywords: active learning, index card match, communication skills.

\section{PENDAHULUAN}

Mata pelajaran Ilmu Pengetahuan Alam (IPA) merupakan salah satu mata pelajaran yang menuntut keterlibatan siswa untuk aktif dalam proses pembelajaran. IPA merupakan ilmu yang berhubungan dengan gejala alam dan kebendaan yang sistematis yang tersusun secara teratur yang berupa kumpulan dari hasil observasi dan eksperimen. Mempelajari IPA memerlukan pemahaman, keterampilan dan kretivitas melalui keterlibatan peserta didik secara aktif baik mental, fisik maupun sosialnya. Selain itu IPA erat kaitannya dengan kehidupan sehari-hari sehingga akan melatih siswa berfikir logis, rasional, kritis atau berpikir secara ilmiah [1-4].

Berdasarkan hasil observasi di SMP Negeri 4 Sewon, proses pembelajaran IPA di sekolah masih belum banyak melibatkan siswa. Strategi ekspositori masih banyak dijumpai di sekolah. Strategi pembelajaran ekspositori adalah strategi pembelajaran yang menekankan kepada proses penyampaian materi secara verbal dari seorang guru kepada sekelompok siswa dengan maksud agar siswa dapat menguasai materi pelajaran secara optimal [5]. Pada strategi ini guru menyampaikan materi secara langsung sehingga siswa tidak dituntut untuk menemukan materi 
pembelajaran. Selama proses pembelajaran berlangsung dimanadijumpai siswa yang cenderung diam (pasif) dan guru lebih mendominasi pada proses pembelajaran maka materi yang disampaikan kurang dipahami oleh siswa. Hal tersebut menyebabkan hasil belajar masih rendah. Hal ini nampak seperti hasil observasi di sekolah yang disajikan pada Tabel 1 .

Pada jiwa seorang siswa juga diperlukan komunikasi secara langsung maupun tidak langsung untuk menunjang kegiatan belajarnya. Siswa perlu memiliki komunikasi yang baik untuk membantunya dalam berinteraksi [6].Yang dijumpai di lapangan yaitu dalam proses pembelajaran di kelas masih banyak peserta didik yang hanya diam saat guru memberikan pertanyaan di kelas, umumnya peserta didik lama sekali untuk menjawab pertanyaan yang diberikan guru. Bahkan, ada beberapa peserta didik yang tidak mau menjawab karena malu dan takut salah menjawab. Guru harus menunjuk peserta didik terlebih dahulu agar mau menjawab pertanyaan, namun ketika menjawab bicaranya masih tersendat-sendat.

Melihat beberapa kasus yang terjadi di sekolah, maka diperlukan adanya strategi pembelajaran yang dapat membuat peserta didik lebih aktif dan peran atau dominasi guru bekurang, yaitu salah satunya adalah menggunakan strategi pembelajaran active learning tipe index card match. Strategi index card match cocok diterapkan pada peserta didik SMP karena strategi ini mengikutsertakan peserta didik secara aktif, mengandung unsur permainan sehingga diharapkan peserta didik tidak bosan dalam belajar IPA [7]. Strategi pembelajaran active learning tipe Index Card Matchmenggunakan kartu soal dan kartu jawaban yang dibuat oleh guru. Kartu soal dan kartu jawaban digunakan untuk mengetahui pemahaman siswa terhadap materi. Langkah strategi pembelajaran active learning tipe index card match pada dasarnya adalah meminta siswa untuk mencocokkan kartu soal dengan kartu jawaban yang dipegang masing-masing siswa kemudian diakhiri dengan klarifikasi dan kesimpulan [5,8-9].

Strategi ini tergolong mudah dan mampu memberi efek yang menyenangkan dan berkesanbagi siswa. Dengan strategi ini, siswa akan menggunakan permainan sebagai media belajar, mereka dapat secara aktif melihat kemudian melakukan daripada hanya mendengarkan dan membaca. Hal ini akan memicu siswa untuk percaya diri dalam menyampaikan pendapat, bertanya maupun berinteraksi. Sehingga melalui strategi ini sudah pasti akan mendukung sertamempermudah siswa untuk memperoleh hasil belajar IPA yang optimal.

Pada penelitian ini, penulis ingin mengetahui keefektifan strategi pembelajaranactive learning tipe index card match. Adapun hipotesis dalam penelitian ini adalah (1) ada perbedaan hasil belajar IPAkelas eksperimen dan kelas kontrol,(2) ada perbedaan hasil belajar IPA siswa kelompok keterampilan berkomunikasi tinggi dan rendah,(3) ada interaksi strategi pembelajaran dan keterampilan berkomunikasi terhadap hasil belajar IPA, (4) strategi pembelajaran active learning tipe index card match lebih efektif dari pada strategi pembelajaran ekspositori.

\section{METODE PENELITIAN}

Penelitian ini dilaksanakan di SMP N 4 Sewon. Penelitian ini merupakan jenis penelitian eksperimen semu (Quasi Experiment).Variabel penelitian adalah(1) strategi pembelajaran active learning tipe Index card match dan strategi pembelajaran ekspositorisebagai variabel bebas, (2) keterampilan berkomunikasi sebagai variabel moderator, dan (3) hasil belajar IPA sebagai variabel terikat. Desain penelitian dapat dilihat pada Tabel 2.Populasi adalah seluruh siswa kelas VII SMP N 4 Sewon. Sampel diambil secara acak, diperoleh yaitu kelas VII B sebagai kelas eksperimen dan VII D kelas kontrol. Teknik pengumpulan data menggunakan (1) teknik tes untuk mengumpulkan data hasil belajar IPA, (2) teknik angket untuk mengumpulkan data siswa berupa keterampilan berkomunikasi, (3) dan teknik dokumentasi untuk mengumpulkan data daftar nama siswa dan foto selama pembelajaran. Uji coba instrumen menggunakan rumus korelasi product momen, sedangkan pada reliabilitas butir soal diuji dengan menggunakan $K R-20$ serta pada reliabilitas angket menggunakan rumus alpha Cronbach. Teknik analisis data ada dua yakni analisis deskriptif dan komparatif. Analisis deskriptif mengacu pada kriteria skala normal ideal [10]. Uji prasyarat analisis berupa uji normalitas sebaran dan uji homogenitas. Uji hipotesis yang digunakan dalam penelitian ini menggunakan uji hipotesis ANAVA dua jalur.

\section{HASIL DAN PEMBAHASAN}

Uji normalitas sebaran menggunakan rumus chi-kuadrat diperoleh $\mathrm{P}=0,073$ untuk kelas eksperimen, dan kelas kontrol diperoleh $\mathrm{p}=0,723$. Hasil keterampilan berkomunikasi untuk kelas eksperimen diperoleh $\mathrm{p}=0,072$ dan kelas kontrol diperoleh $\mathrm{P}=0,064$. Berdasarkan dari hasil perhitungan yang diperoleh maka dapat dinyatakan bahwa data yang digunakan dalam penelitian ini berdistribusi normal. Sedangkan untuk uji homogenitas varian menggunakan rumus uji-F diperoleh hasil belajar IPA pada kelas eksperimen dan kelas kontrol nilai $F_{\text {hitung }}=1,219$ dengan $\mathrm{p}=$ 0,292 . Untuk keterampilan berkomunikasi tinggi dan rendah diperoleh $F_{\text {hitung }}=1,327$ dengan $\mathrm{p}=$ 0,273 . Berdasarkan dari hasil di atas dapat dikatakan bahwa sebaran data hasil belajar IPA dan keterampilan berkomunikasi adalah homogen. 
Uji hipotesis menggunakan Anava dua jalur dengan bantuan program perangkat lunak Seri Program Statistik (SPS) edisi Sutrisno Hadi dan Yuni Pamardiningsih diperoleh hasil pada tabel 3.

Berdasarkan tabel diatas maka dapat disimpulkan sebagai berikut: (1) $\mathrm{F}_{\mathrm{A} \text { hitung }}=129,391$ dengan $\mathrm{p}=0,000 ; \mathrm{p} \leq 0,01$ maka ada perbedaan hasil belajarIPA yang sangat signifikan antara kelas eksperimen dengan kelas kontrol, (2) $\mathrm{F}_{\mathrm{B}}$ hitung $=$ 259,557 dengan $\mathrm{p}=0,000$, maka ada perbedaan yang sangat signifikan antara hasil belajar IPA pada kelompok keterampilan berkomunikasi tinggi dan rendah. (3) $F_{\text {ABhitung }} 7,064$ dengan $p=0,010$, maka dapat disimpulkan bahwa ada interaksi yang sangat signifikan antara strategi pembelajaran dan keterampilan berkomunikasi terhadap hasil belajar IPA.

Tabel 1. Rata-Rata Hasil Penilaian Akhir Semester (PAS) Mata Pelajaran IPA Tahun Pelajaran $2017 / 2018$

\begin{tabular}{lcc}
\hline Kelas & Jumlah siswa & $\begin{array}{c}\text { Rata-rata hasil } \\
\text { PAS }\end{array}$ \\
\hline VII A & 32 & 52,26 \\
VII B & 32 & 53,51 \\
VII C & 32 & 45,39 \\
VII D & 32 & 48,28 \\
\multicolumn{2}{c}{ Rerata PAS } & 49,89 \\
\hline
\end{tabular}

Tabel 2. Desain Penelitian

\begin{tabular}{|c|c|c|c|}
\cline { 3 - 3 } \multicolumn{2}{c|}{} & \multicolumn{2}{c|}{$\begin{array}{c}\text { Strategi } \\
\text { pembelajaran }\end{array}$} \\
\cline { 3 - 4 } \multicolumn{2}{c|}{} & $\begin{array}{c}\text { ICM } \\
\left(\mathrm{A}_{1}\right)\end{array}$ & $\begin{array}{c}\text { Eksposit } \\
\text { ori }\left(\mathrm{A}_{2}\right)\end{array}$ \\
\hline $\begin{array}{c}\text { Keterampilan } \\
\text { berkomunika } \\
\text { si }\end{array}$ & $\begin{array}{c}\text { Tinggi } \\
\left(\mathrm{B}_{1}\right)\end{array}$ & $\mathrm{A}_{1} \mathrm{~B}_{1}$ & $\mathrm{~A}_{2} \mathrm{~B}_{1}$ \\
\cline { 2 - 4 } & $\begin{array}{c}\text { Rendah } \\
\left(\mathrm{B}_{2}\right)\end{array}$ & $\mathrm{A}_{1} \mathrm{~B}_{2}$ & $\mathrm{~A}_{2} \mathrm{~B}_{2}$ \\
\hline
\end{tabular}

Tabel 3. Ringkasan Anava Dua Arah

\begin{tabular}{|c|c|c|c|c|c|}
\hline Sumber & $\mathrm{JK}$ & $\mathrm{Db}$ & RK & $\mathrm{F}$ & $\mathrm{P}$ \\
\hline Antar A & 129,391 & 1 & 129,391 & 44,318 & 0,000 \\
\hline Antar B & 757,795 & 1 & 757,795 & 259,557 & 0,000 \\
\hline Inter $\mathrm{AB}$ & 20,624 & 1 & 20,624 & 7,064 & 0,010 \\
\hline Dalam & 175,175 & 60 & 2,920 & -- & -- \\
\hline Total & 1082,984 & 63 & -- & -- & -- \\
\hline
\end{tabular}

Hasil belajar siswa pada penelitian ini diperoleh dari nilai pretest dan posttest baik pada kelas eksperimen yang pembelajarannya menggunakan strategi pembelajaran active learning tipe Index Card Match dan kelas kontrol yang menggunakan strategi pembelajaran ekspositori. Pada penelitian ini, hasil belajar IPA siswa pada strategi pembelajaran active learningtipe Index Card Match dan strategi pembelajaran ekspositori terlihat konsisten pada masing-masing kategori keterampilan berkomunikasi. Artinya hasil belajar siswa yang mempunyai keterampilan berkomunikasi tinggi lebih baik dibandingkan dengan siswa yang mempunyai keterampilan berkomunikasi rendah.

Hasil belajar IPA kelas eksperimen memiliki rata-rata skor 20,440 dan terletak pada interval $19,513 \leq X \leq 26$ dimana termasuk kategori sangat tinggi pada kriteria skala normal. Sedangkan hasil belajar kelas kontrol memiliki rata-rata skor 17,590 yang terletak pada interval $15,171 \leq X<$ 19,513 dan termasuk kategori tinggi. Berdasarkan data tersebut maka kesimpulan keempat (4) yang dapat ditarik adalah strategi pembelajaran active learning tipe index card matchlebih efektif dari pada strategi pembelajaran ekspositori. Hal ini senada dengan penelitian yang dilakukan oleh Kasmadi dan Kamila, yang menyebutkan bahwa penerapanstrategi pembelajaran aktif tipe index card matchdapat meningkatkan prestasi belajar siswa pada pokok bahasan Koloid di kelas XI IPA SMA Negeri 2 Siak Hulu [11].

Hasil belajar IPA yang pembelajarannya menggunakan strategi pembelajaran active learning tipe Index Card Match memiliki hasil lebih tinggi dari pada dengan strategi pembelajran ekspositori. Hal ini disebabkan dengan strategi pembeljaran active learning tipe Index Card Match peserta didik lebih mudah memahami materi yang dipelajari, waktu yang digunakan untuk belajar lebih efektif karena peserta didik terlibat langsung dalam kegiatan pembelajaran sehingga dapat meningkatkan aktivitas peserta didik dalam pelajaran IPA. Hasil penelitian sebelumnya yang dilakukan Rahmawati dkk [12] menyebutkan bahwa penerapan strategi Index Card Match akan membuat peserta didik lebih aktif, teliti, dan mampu bekerja sama. Hal ini terjadi karena semua 
peserta didik aktif dalam pencairan kartu pasangannya. Strategi ini juga melatih peserta didik untuk memahami materi pelajaran karena sebelum mencari pasangannya peserta didik harus paham dengan materi yang ada dikartunya.

Penggunakan kartu pada strategipembelajaran active learning tipeIndex Card Match akan membuat siswa sibuk untuk mencari pasangannya. Siswa akan berkomunikasi dengan siswa yang lainnya untuk saling mencocokkan kartu. Pada interaksi ini siswa akan menerapkan keterampilan bertanya, menjawab dan mengemukakan pendapat atau gagasan-gagasan yang mendukung pernyataannya. Dengan demikian siswa akan terlibat secara aktif dalam proses pembelajaran. Setelah pasangan kartu ditemukan maka siswa akan melakukan klarifikasi dan terakhir adalah menyimpulkan.

Strategi pembelajaran active learning tipeIndex Card Match dapat menumbuhkan rasa gembira, nyamanselama pembelajaran karena materi menjadi lebih menarik perhatian siswa materi melalui wahana bermain. Siswa tidak akan menjadi bosan dalam proses pembelajaran. Siswa akan lebih memperhatikan guru karena tahu bahwa nanti akan ada permainan yang kaitannya dengan pemahaman konsep materi. Siswa tidak lagi sungkan untuk menyampaikan pendapat baik langsung maupun tidak langsung. Dengan menggunakan strategi ini pada kelas eksperimen diperoleh hasil belajar yang berada dalam kategori sangat tinggi. Asumsinya bahwa jika siswa senang, nyaman untuk belajar maka materi yang disampaikan oleh guru dapat terserap dengan baik sehingga ketika diberikan tes hasil belajarakan memberikan hasil yang maksimal.

\section{KESIMPULAN DAN SARAN}

Berdasarkan hasil penelittian dan pembahasan maka dapat disimpulkan: (1) ada perbedaan hasil belajar IPAkelas eksperimen dan kelas kontrol,(2) ada perbedaan hasil belajar IPA siswa kelompok keterampilan berkomunikasi tinggi dan rendah,(3) ada interaksi strategi pembelajaran dan keterampilan berkomunikasi terhadap hasil belajar IPA, (4) strategi pembelajaran active learning tipe index card match lebih efektif dari pada strategi pembelajaran ekspositori.

Strategi pembelajaran active learning tipe index card match dapat sebagai alternatif dalam proses pembelajaran untuk meningkatkan hasil belajar siswa. Hal ini karena dalam strategi pembelajaran active learning tipe index card match akan menciptakan suasana menyenangkan dan siswa aktif selama proses pembelajaran.

\section{DAFTAR PUSTAKA}

[1] Hodson, D. (2003). Time for action: Science education for an alternative future. International journal of science education, 25(6), 645-670.

[2] Suryadin, S., Merta, I. W., \& Kusmiyati, K. (2017). Pengaruh Model Pembelajaran Visual Auditorial Kinestetik (VAK) Terhadap Motivasi Dan Hasil Belajar Ipa Biologi Siswa Kelas VIII SMP Negeri 3 Gunungsari Tahun Ajaran 2015/2016. Jurnal Pijar Mipa, 12(1).

[3] Widyatiningtyas, R. (2006). Pembentukan Pengetahuan Sains, Teknologi, dan Masyarakat dalam Pandangan Pendidikan IPA. EDUCARE, 1(2).

[4] Wijayanti, A. (2016). Implementasi model pembelajaran kooperatif tipe tgt sebagai upaya meningkatkan pemahaman konsep fisika dasar mahasiswa pendidikan IPA. Jurnal Pijar Mipa, 11(1).

[5] Situmorang, P. C., \& Hasanah, U. (2016). Perbedaan Hasil Belajar Siswa Menggunakan Strategi Pembelajaran Aktif Tipe Index Card Match dengan Card Sort pada Materi Organisasi Kehidupan. Jurnal Pelita Pendidikan, 4(2).

[6] Dono, I. O. (2016). Penerapan Bimbingan Kelompok Teknik Permainan Untuk Meningkatkan Kemampuan Komunikasi Interpersonal Siswa SMP Negeri 2 Menganti Gresik. Jurnal BK UNESA, 6(3).

[7] Suprijono, A. 2012. Cooperative Learning Teori \& Aplikasi PAIKEM. Yogyakarta: Pustaka Pelajar.

[8] Bowo-Sugiharto, N. A. S. S. (2014). Perbandingan Hasil Belajar Biologi Strategi Pembelajaran Aktif Tipe Make A Match dan Card Sort. Bio-Pedagogi, 3(1), 88-98.

[9] Situmorang, P. C., \& Hasanah, U. (2016). Perbedaan Hasil Belajar Siswa Menggunakan Strategi Pembelajaran Aktif Tipe Index Card Match dengan Card Sort pada Materi Organisasi Kehidupan. Jurnal Pelita Pendidikan, 4(2).

[10] Saifuddin, A. 2013. Reliabilitas dan Validitas Edisi 4. Yogyakarta: Pustaka Pelajar.

[11] Asmadi, S. H., \& Kamila, Y. (2013). Peningkatan Prestasi Belajar Koloid Melalui Penerapan Strategi Pembelajaran Aktif Index Card Match Pada Siswa SMAN 2 Siak Hulu-Riau. Jurnal Pendidikan, 2(2).

[12] Rahmawati, A. D., Rosyidi, A., \& Probosari, R. M. (2011). Hasil Belajar Biologi Menggunakan Strategi Pembelajaran Aktif Index Card Match Ditinjau dari Motivasi. Jurnal Pendidikan Biologi, 3(3), 27-40. 